Article

\title{
The Market Sentiment Trend, Investor Inertia, and Post-Earnings Announcement Drift: Evidence from Korea's Stock Market
}

\author{
Heejeong Shin ${ }^{1}$, Hyejeong Shin ${ }^{2} \mathbb{C}$ and Su-In Kim ${ }^{3, *}$ \\ 1 School of Business, Ewha Womans University, 52 Ewhayeodae-gil, Seodaemun-gu, Seoul 3760, Korea; \\ hjshin0823@gmail.com \\ 2 Department of Business Admnistration, Kyonggi University, 154-42 Gwanggyosan-ro, Yeongtong-gu, \\ Suwon-si, Gyeonggi-do 16227, Korea; hj_shin@kyonggi.ac.kr \\ 3 College of Business Management, Hongik University, 2639, Sejong-ro, Jochiwon-eup, Sejong-si 30016, Korea \\ * Correspondence: suinkim@hongik.ac.kr; Tel.: +82-44-860-2056
}

Received: 16 August 2019; Accepted: 16 September 2019; Published: 19 September 2019

\begin{abstract}
We investigated whether post-earnings announcement drift (PEAD) in the Korean stock market is related to investor inertial behavior under a directional trend in market sentiment. Given that investors tend to procrastinate due to their belief in the persistence of the current market's condition and thus underreact to earnings information, we examined whether this investor inertia influences the drift in stock price following an earnings announcement. Our findings show that when the market sentiment continues to shift upwardly (downwardly) over the pre- and post-earnings announcement period, positive (negative) drift occurs. Note that these results are robust to control for the effect of market sentiment at a specific point in time. We suggest that investors do not fully respond to new earnings information due to investor inertial behavior under the market sentiment with a consistent trend. Overall, our study sheds light on a determinant of PEAD as one of the market anomalies in terms of investors' cognitive bias by documenting the relation between PEAD and investor inertia.
\end{abstract}

Keywords: market sentiment; investor inertia; post-earnings announcement drift; trend of market sentiment; cognitive bias

\section{Introduction}

We investigate whether post-earnings announcement drift is associated with investor inertial behavior under a directional trend in market sentiment in the Korean stock market (KSE). Post-earnings-announcement drift (henceforth, PEAD) is defined as the anomalous stock price behavior in a capital market in which stock price moves continuously with directional unexpected earnings even after the earnings information is announced [1,2]. Given that the PEAD phenomenon is generally explained by a delayed stock response due to investors' underreaction to earnings news (i.e., unexpected earnings), we focus on investor inertia, a type of cognitive bias in psychology, as an influential factor in PEAD. Market sentiment generally represents the market mood at any given time. Among investors in a practical field, it is referred to as stock valuation or investment strategy. It is known that higher (lower) sentiment indicates that the overall market state is more (less) optimistic. According to the literature on investor inertia, investors tend to procrastinate their decision making and retain their initial decisions by relying on existing information, and this tendency is known to be pronounced under a stable environment [3]. In physics, inertia is defined as the property of an object's resistance to change in velocity, which is also called Newton's first law. That is, due to inertia, an object will continue to stay in uniform motion unless an external force is applied, making it change its course or speed. Understanding investors' inertia in a capital market is important because it enables 
us to address critical issues related to the inefficient market (i.e., PEAD) and their role in shaping stock prices for securities investors hold $[4,5]$. The following article clearly presents a tendency for investor inertia in Korea. "... the law of inertia in psychology is defined as an investor's vague belief that a current psychological state or situation will remain unchanged for several periods. For instance, four years ago, many experts stressed that investors should sell real estate in provincial cities and buy properties in metropolitan areas while announcing a negative forecast for apartment prices in rural areas. However, what happened to the markets? The price of real estate in provincial cities soared sharply, and on the contrary, real estate prices in metropolitan areas plummeted dramatically. Why do these results occur? The reason is that the law of inertia influences experts' and investors' beliefs. At the time, the price of local apartments had been continuously low for about five years, and thus, this situation made both experts and investors overconfident that it would be too difficult to rebound ...." Investors' psychology, "the law of inertia" [6].

In this context, we postulate that a continuation of directional market sentiment induces investor inertial behavior and hypothesize that PEAD is systematically related to investors' underreaction, which is attributable to investor inertia under the market sentiment with trend. Allowing us to be able to predict future stock returns by showing a continuation of stock price movement, PEAD resembles the price momentum documented in finance literature. However, those two phenomena are different in that while price momentum allows investors to obtain the hedge returns based on past returns information [7-9], PEAD allows investors to obtain the hedge returns based on unexpected earnings information in the earnings announcement period $[1,10]$. In this paper, we focus on PEAD analysis covering investors' underreaction to earnings information due to investor inertia in the situation in which market sentiment has a directional trend. That is, when investors lie in the market mood which changes with a trend of increase or decrease, investor inertial behavior occurs, which leads to the delayed stock price reaction. To be specific about the relation between PEAD and change in market sentiment in connection with investor inertia, investors are likely to expect the current market state to last going forward and adhere to their prior belief based on the current state of the market sentiment. To delineate our prediction in terms of market pricing, if market sentiment has continuously moved upward from the previous period, then considering a target firm over-valued for a certain period of time, investors are likely to ignore especially positive unexpected earnings that incorporate information about future earnings increase (that's where the inertia comes in). However, as investors understand the implication of positive unexpected earnings as time goes by, stock price reflects such investors' behavior and thus stock price drift occurs on positive unexpected earnings. Conversely, if the market sentiment has continuously moved downward from a previous period, stock price drift occurs on negative unexpected earnings.

While prior studies document that stationary market sentiment plays a crucial role in moving share prices in the stock market [4], our intuition provides a new perspective on the effect of market sentiment on the stock market by suggesting that moving sentiment over the earnings announcement periods also influences market pricing aside from the level of market sentiment at a specific point in time.

This is rather practically evident. Most articles of news media on market sentiment often deliver the information about the change in market sentiment (i.e., trend) with investors' behavior also forecasted accordingly. Also, technical analysis in finance means investors tend to forecast future in the basis on market trend, rather than the level of market state. It implies that the information of market sentiment trend is worth it for investors to make decisions. In this context, we posit it is based on a change in market state by the time that investors take actions, and in such respect, we revisit the relation between stock price drift and market sentiment, indicating discriminative analysis from previous research.

The Korean stock market is characterized by the relatively high participation of individual investors among the emerging markets, where institutional investors are major market players [11]. 
Since individual investors are likely to be affected by the market sentiment [12], the Korean stock market is generally considered sensitive to the market sentiment.

However, very little research has examined the relation between market sentiment and investor responsiveness to earnings news in Korea. Moreover, relative to the level of market sentiment at a specific point in time, studies on the effect of the market sentiment with trend on market inefficiency are absent, as far as we know.

Using quarterly data from 2002 Q4 to 2017 Q4 in the Korean stock market (Korea Stock Exchange), we conduct portfolio tests by upward trend and downward trend in market sentiments and run a regression analysis. We employ the composite index suggested by a prior study [13] as a proxy for market sentiment. We find that the magnitude of drift in stock price subsequent to an earnings announcement is significantly related to the market sentiment with trend over two periods prior to and following an earnings announcement. More specifically, for an upward (downward) trend in market sentiment, PEAD occurs on positive (negative) unexpected earnings, and these results are robust after controlling for the effect of the state of the market sentiment at a specific point in time (i.e., both prior to and following earnings announcements). Additionally, we show that the subsequent abnormal return following an earnings announcement is incrementally lower when the prior-sentiment is higher but indifferent to following-sentiment. Overall, our findings suggest that the stock price drift is affected by the investor inertia under a continuation of directional market sentiment as a proxy for a stable environment, not subsuming the effect of market sentiment in a period following earnings announcements per se.

By linking post-earnings announcement drift to the market sentiment with trend, our study provides quite different insights from prior studies into market anomalies examining subsequent abnormal returns relative to the level of market sentiment at a specific point in time. This paper contributes to the academic and practical accounting fields in several ways. First, our research findings add another determinant of PEAD to the literature by documenting the relation between PEAD and investor inertial behavior. Second, by investigating how an investor's cognitive bias (i.e., problem of inertia) affects abnormal returns in earnings-based trading strategies, our study is useful to professional investors who try to capture abnormal returns from market mispricing. Third, our findings are also valuable to academic fields interested in understanding stock price behavior and estimating a firm's intrinsic value.

This paper is organized as follows. In Section 2, we discuss the background and develop the hypothesis. The methodology, including sample selection, variable definitions, and model specification, is presented in Section 3. We provide our empirical test results in Section 4. Finally, Section 5 concludes the paper.

\section{Background and Development of Hypothesis}

\subsection{Post-Earnings Announcement Drift (PEAD) and Investor Inertial Behavior}

PEAD is defined as the phenomenon in which stock returns drift continuously for several periods in the direction of unexpected earnings following earnings announcement dates [1,2]. Since this contradicts the efficient market hypothesis, which suggests that stock price fully and immediately reflects the public information for future earnings in an earnings announcement period, PEAD is generally understood as an accounting-based market anomaly. While a large number of studies have explained the causes of this phenomenon in terms of transaction cost, risk, and a methodological problem [14-16], the most common explanation is investors' underreaction to the underlying information in unexpected earnings that incorporate the information about future earnings change $[10,17]$. The evidence is similar to the documents in Korea. Nah [18] documents that PEAD exists in the Korean stock market and that the magnitude of such drift is similar to that in the US stock market. Since Nah [18] reported the existence of PEAD, several studies have shown that information uncertainty [19] and investor sophistication $[20,21]$ are related to this phenomenon. 
The factors determining the magnitude of PEAD are summarized in three dimensions. First, the proxies for the information environment such as firm size, analyst following, accounting disclosure policy, and Big 4 audit firms are negatively related to the extent of PEAD [14,15,22-26]. This suggests that the rich environment of information improves the informational efficiency for investors in interpreting earnings information, consequently lowering the magnitude of PEAD.

Second, earnings' quality affects the magnitude of PEAD $[27,28]$. To the extent that PEAD is attributable to the investors' ignorance of the property of earnings, investors' underreaction to more persistent (volatile) earnings results in a greater (lesser) PEAD magnitude. This argument is associated with investors' conservatism in which investors tend to react more efficiently to bad news, since the current earnings of firms with loss or negative unexpected earnings is less persistent. Third, the magnitude of PEAD decreases with investor sophistication [22,29]. More sophisticated investors such as institutional investors or foreign investors in emerging markets are superior in disentangling future earnings information through the financial statement analysis and are likely to benefit from their private information as well. In this context, the firms with more sophisticated investors reveal less PEAD.

Several recent studies in behavioral finance document that investors' underreaction to earnings information is attributable to investors' cognitive biases [30,31]. While a conventional asset pricing theory documents that investors are rational and can promptly rebalance their portfolios [32], this literature offers evidence that they have limited attention and even contribute to the emergence of mispricing. The general concept that the studies document is that when new earnings information arrives, investors are inclined to look for other information such as heuristics to be convinced of their prior belief [33-35]. Furthermore, they can be over-confident in their belief and cling to their initial decision. As a result, they often do not change their portfolio positions for an extended period in the context of investor inertial behavior [3,36,37].

Inertia, which is referred to as the tendency to stick to an initial decision or procrastinate decision making in an equity market, is the norm for a wide range of investors [5]. Baker et al. [3] document the consequences of investor inertia for a stock-for-stock merger, reporting that acquirers tend to experience a smaller negative price impact when investors of target firms are inertial in evaluating new shares in the merger. This means that the inertial behavior of investors may lead them to overlook valuable information for assets pricing. A growing number of empirical research studies in household finance also show that retail investors are inactive in portfolio management $[36,38,39]$, which is often a rational decision given their limited attention [5]. For example, Madrian and Shea [39] suggest that the default behavior resulting from participants' inertia works in the determination of individual savings behavior by showing evidence that $401(\mathrm{k})$ participation is significantly higher under automatic enrollment. Agnew et al. [38] also document substantial inertia among investors, particularly in their retirement accounts, with close to $90 \%$ never altering their portfolios. Bilias et al. [36] report that most stock account owners (up to 70\%) exhibit portfolio inertia in investor trading behavior. Hirshleifer and Welch [37] show analytical evidence that investors exhibit inertia behavior, especially when their past actions are highly informative and they are prone to memory loss. Taken together, these investors' limited attention may result in investors' underreaction to new earnings information, consequently causing the stock price to diverge from the firm's intrinsic value.

\subsection{Research Model Specification}

Several papers on the effect of investors' cognitive bias on stock return patterns state that market sentiment affects market pricing [40-42]. Market sentiment is generally defined as the level of the market state representing the extent that investors are optimistic or pessimistic about future performance. Specifically, high (low) market sentiment reflects the market's optimism (pessimism). Related literature documents that stock prices, under a high (low) sentiment, generally tend to be upwardly (downwardly) biased, indicating that stock prices are likely to be over-valued (under-valued) due to investor optimism (pessimism). However, mispriced stocks ultimately do revert to fundamental 
values as new information arrives. Stock returns for over-valued (under-valued) firms due to high (low) sentiment, in turn, decrease (increase) after earnings announcements. To summarize, the subsequent stock returns decrease with the level of market sentiment.

To the extent that PEAD occurs due to investors' delayed reaction related to stock price correction, the market sentiment prior to earnings announcements can be a factor in the magnitude of PEAD. Regarding this argument, Mian and Sankaraguruswamy [43] show that the stock price reaction varies with respect to the earnings news with investors' expectations based on the level of market sentiment. They report that stock price sensitivity to positive (negative) unexpected earnings is higher during periods of high (low) sentiment than during periods of low (high) sentiment. This indicates that the level of market sentiment would have an effect on the delayed stock price drift on unexpected earnings as well, and also, PEAD on signed unexpected earnings is amplified in different directions by high/low sentiment. Park [44], who found evidence on the effect of market sentiment on market pricing of corporate earnings in the Korean stock market, also documents the asymmetric effect on cumulative abnormal returns on unexpected earnings.

\subsection{Research Motivation and Hypothesis Development}

Previous literature documents the effect of the market sentiment level at a specific point in time (i.e., pre-announcement period) on the market's response to earnings news. However, market sentiment states may change to focus on other aspects over the periods of earnings announcements, and their transitions themselves may contain distinctive information for forecasting the future performance of a firm. In general, investors are likely to take the trend of the market mood into account when forming their expectation of how the market mood will change in the future [45]. This leads us to a further question on whether the trend in market sentiment between pre- and post-earnings announcement periods influences stock price reaction to earnings announcements.

Stock price is ultimately formed by the convergence of all investors' expectations, and investors' behavior intervenes in that process [22]. To explain investors' behavior with respect to the different responses to earnings news by the market sentiment with trend, we employ the notion of "investor inertia," known pervasively for a type of cognitive bias by which investors suffer from erroneous decision making. Extant studies suggest that people tend to procrastinate and retain their initial decision, and further, that such investor inertial behavior arises largely under a stable environment $[3,37,46]$. In this context, we postulate a continuation of the trend in market sentiment for the stable information environment and pose that a tendency of investor inertia is noticeable when the market sentiment moves in the same direction (does not fluctuate) over a period.

If investor inertial behavior is induced by the market sentiment trend and thus contributes to investors' underreaction to earnings information, the drift in stock price is systematically related to the trend in market sentiment. Based on investor inertia, we conjecture that when the current market state continues according to its trend (i.e., upward), investors will adhere to their investment decision as they are overwhelmed by their expectation that the sentiment effect has been driving the stock price, and thus their stocks are overvalued [41]. As a result, they do not fully react to earnings information at earnings announcements. To be specific, in terms of market pricing with respect to market sentiment, if the market sentiment has been continuously moving upward, considering a target firm that is over-valued, investors are likely to ignore good news, and thus stock price drift occurs on positive unexpected earnings.

Conversely, if the market sentiment has been continuously moving downward, investors consider target firms that are under-valued and are likely to underreact to bad news. As a result, stock price drift occurs on negative unexpected earnings. Taken together, investor inertia under the market sentiment with trend incurs investors' underreaction to public earnings information (i.e., unexpected earnings), resulting in stock price drift subsequent to the earnings announcement period. Thus, we predict that the magnitude of positive (negative) PEAD would be positively related to the upward (downward) trend in market sentiment, and we hypothesize as follows: 
Hypothesis: The magnitude of drift in stock price following earnings announcements is systematically related to the market sentiment with trend.

\section{Methodology}

\subsection{Data and Sample Selection}

The sample of this study consists of common stocks for KSE (Korea Stock Exchange)-listed firms between 2002 Q4 and 2017 Q4. Required to measure the standardized unexpected earnings (SUE) by a time series forecast model (see Section 3.2.1), quarterly financial data of at least eight-consecutive quarters should be available. That is, we include any focal firm-quarters that retain the previous seven-consecutive quarter earnings data even if those firms enter or exit at any time during the sample period. However, the interim reports of financial statements have been allowed to be released since 2001 in Korea. For this reason, our main analysis period starts from 2002 Q4.

We retrieve quarterly earnings data, daily stock prices, and other financial variables from the Kis-value II database of NICE Investors Service Co, Ltd. As a proxy for the magnitude of PEAD, we use cumulative abnormal returns over the 60 trading days following the earnings announcement and obtain the earnings announcement dates from the Korean Exchange.

Table 1 shows the sample selection criteria. Our sample starts from the current observations of firms listed on the Korean Stock Exchange (KSE), as at 31 December 2017. Then, firms in financial and insurance and with non-December fiscal year ends are excluded. The final sample is 15,315 firm-quarters, restricted to only the firms with both eight-consecutive quarters of earnings and 60-trading days cumulative returns even if those firms enter or exit at any time during the sample period. We winsorize at $1 \%$ of the top and bottom in each variable's distribution to attenuate the effect of outliers.

Table 1. Descriptive statistics.

\begin{tabular}{ccc}
\hline Sample Selection Criteria & Firms & Firm-Quarters \\
\hline $\begin{array}{c}\text { Firms listed on the Korean Stock Exchange (KSE) at 31 December 2017 } \\
\text { (Less) Firms in financial and Insurance industry } \\
\text { (Less) Firms with non-December fiscal year-ends }\end{array}$ & 929 & $(194)$ \\
Total Firms & $(15)$ & \\
\hline $\begin{array}{c}\text { Firms for which 8-consecutive quarterly earnings are available } \\
\text { (Less) Firms for which 60-trading days cumulative returns are not available } \\
\text { (Less) Firms for which other control variables are not available }\end{array}$ & $\mathbf{7 2 0}$ \\
\hline Final sample firm-quarters & $(6,528)$ \\
\hline
\end{tabular}

\subsection{Variable Definitions}

\subsubsection{Standardized Unexpected Earnings (SUE)}

We estimate the standardized unexpected earnings (SUE) using a time series forecast of earnings in accordance with prior literature (Foster [14]; Ball and Bartov [17]; Nah and Shin [21]. Unexpected earnings $\left(E P S_{i, t}-E P S_{i, t-4}\right)$ estimated based on random walk assumption are standardized to be those per one unit standard deviation: $S U E_{i, t}=\frac{E P S_{i, t}-E P S_{i, t-4}}{\sigma_{i, t}}, E P S_{i, t}=$ quarterly earnings per share, $E P S_{i, t-4}=$ earnings per share in the same quarter in the previous year, and $\sigma_{-}(\mathrm{i}, \mathrm{t})=$ the standard deviation of unexpected $\left(E P S_{i, t}-E P S_{i, t-4}\right)$ over the prior eight quarters.

\subsubsection{Market Sentiment Index}

As the variable on market sentiment, we employ the Korean market sentiment index suggested by Kim and Byun [13]. They follow Baker and Wurgler's [47] principal components analysis and create a monthly market sentiment index by using six individual sentiment proxies: (1) monthly 
trading imbalance of individual investors (BSI), (2) customer expectation index for business cycle (CEI), (3) stock-investing customers' deposits (CD), (4) capital raising ratio of equity shares (SR), (5) turnover ratio of listed stocks (TURN), and (6) market returns of the Korea Stock Price Index (KOSPI). They use these factors to linearly construct a market sentiment index (SENT) following Baker and Wurgler [47]. A high (low) sentiment index indicates investors' optimism (pessimism) about the future performance of firms. This index is deemed to be validated for explaining the market sentiment state in the Korean stock market $[13,44]$.

To test our hypothesis, we measure the difference in market sentiment between quarters as a proxy for the market sentiment with trend. Even though the monthly market sentiment is volatile, market mood is perceived over a long period of time. For instance, an expansion or recession period in a macroeconomic cycle is based on time periods of several months or years. For this reason, we posit that the change in market sentiment between quarters will indicate the average continuous direction of the sentiment. Moreover, we analyze our data on a quarterly basis since we examine the magnitude of PEAD in response to investors' underreaction to quarterly earnings information. Therefore, the proxy for the trend in market sentiment is bound by the measurement taken on a quarterly basis.

\subsubsection{Model Specification}

We run the following regression model to test our hypothesis. To control some estimation biases since our data, as panel data, entail the cross-sectional or time-serial correlation within residuals, we include dummy variables for year and industry in the model. Furthermore, all regression models use t-statistics based on robust standard errors clustered at firm level [48].

$$
\begin{aligned}
\text { AR60 }_{i, t} & =\beta_{0}+\beta_{1} \text { DSUE }_{i, t}+\beta_{2} \text { DSUE }_{i, t} \times \text { CHSENT }_{t}+\beta_{3} \text { CHSENT }_{t} \\
& +\beta_{4} \text { PSENT }_{t}+\beta_{5} \text { ASENT }_{t}+\beta_{6} \text { SIZE }_{i, t}+\beta_{7} \text { VOLM }_{i, t} \\
& +\beta_{8} \text { VALUE }_{i, t}+\beta_{9} \text { ROA }_{i, t}+\beta_{10} \text { MTB }_{i, t}+\beta_{11} \text { LEVER }_{i, t} \\
& +\beta_{12} \text { FOLLOW }_{i, t}+\beta_{13} \text { FOR }_{i, t}+\beta_{14} \text { BETA }_{i, t} \\
& +\beta_{15} \text { VOLATI }_{i, t}+\beta_{16} \text { BIG4 }\left(\text { Indicator }_{i, t}\right. \\
& +\sum \text { Year Effect }+\varepsilon_{i, t}
\end{aligned}
$$

In this model, AR60 represents cumulative size-adjusted abnormal returns (SAR60) and market-adjusted abnormal returns (MAR60), measured over the 60 trading days from the next day of the quarterly earnings announcement. Each cumulative abnormal return is calculated as the sum of the daily abnormal return over the 60 trading days. Size-adjusted daily abnormal returns (SAR) are measured as daily stock returns less the average returns based on firm size. To calculate the average returns based on firm size, we form 10 portfolios by sorting on market value at the beginning of the year and then calculate abnormal returns by subtracting portfolio average returns from firm-specific returns. Market-adjusted daily abnormal returns (MAR) are measured as daily stock returns less average daily stock returns of market. DSUE is the decile ranking (0-9) of SUE divided by 9. PSENT is the average market sentiment of the quarter prior to the earnings announcement period, and ASENT is the average market sentiment of the quarter with the earnings announcement. Our interesting variable is CHSENT, represented by DSENT or CSENT. DSENT denotes the indicator variable equal to 1 if the average market sentiment increases over two quarters ( $t-1$ and $t)$ prior to and at the earnings announcement period and equal to 0 otherwise, CSENT equals the changes in the market sentiment over two quarters ( $t-1$ and $t)$ prior to and at the earnings announcement period.

Importantly, the interaction term (DSUE*CHSENT) captures the incremental effects of the change in market sentiment between pre- and post-earnings announcement periods on abnormal returns, conditioned on the SUE decile rankings. Note that the effects of both the prior-sentiment (PSENT) and the following-sentiment (ASENT) on subsequent abnormal returns are controlled in this regression model as independent variables to capture the distinct effect of market sentiment pre-and post-announcement. If the upward (downward) change in market sentiment incrementally affects the magnitude of positive 
(negative) PEAD, we expect the slope coefficient of the interaction term to be statistically significant and positive.

We include the following characteristics in the regression model to control for the effects of the variables associated with the magnitude of PEAD: (1) information environment (SIZE, FOLLOW, FOR), (2) market trading frictions (VOLM, VALUE), and (3) audit quality (BIG4). Further, we control for the effects of the variables associated with the abnormal returns [49,50]: (1) financial profitability and/or firm growth (ROA, MTB) and (2) risk (VOLATI, BETA, LEVER). Specifically, SIZE equals logarithm of the market value, FOLLOW equals the number of analysts' followings, FOR equals foreign investor ownership, VOLM equals logarithm of average trading volume over the quarter, VALUE equals logarithm of average trading value over the quarters, BIG4 denotes an indicator variable for audit firm size which is set to 1 if the auditor is one of Big 4 audit firms (PwC Samil, Deloitte Korea, Samjong KPMG, and Earnst and Young Korea) and 0 otherwise, ROA equals return on assets, calculated as net income to total assets, MTB equals market-to-book value, VOLATI equals stock returns volatility, BETA equals firm beta based on daily stock returns, and LEVER equals debt ratio measured as total liability divided by total assets.

\section{Empirical Results}

\subsection{Descriptive Statistics and Correlation Analysis Results}

Table 2 reports the descriptive statistics for all test variables. Market sentiment variables (PSENT, ASENT, DSENT, and CSENT) show their distribution based on all firm-quarter observations. The mean value of 0.532 on DSENT means that approximately $53 \%$ of sample experiences the upward shift of market sentiment at the next quarter. The gap between the mean and median as well as the high standard deviation of the main variable, SUE, and the other control variables such as FOR, FOLLOW, and VOLATI indicate the skewed distribution of the variables. To eliminate any potential bias caused by their skewness, we use the decile rankings of all the independent variables in the regression analysis except for market sentiment variables.

Table 2. Descriptive statistics $(N=15,315)$.

\begin{tabular}{cccccccc}
\hline Variables & MIN & $\mathbf{2 5 \%}$ & MEAN & MEDIAN & $\mathbf{7 5 \%}$ & MAX & STD \\
\hline PSENT & -1.477 & -0.718 & -0.204 & -0.181 & 0.256 & 1.425 & 0.673 \\
ASENT & -1.477 & -0.386 & 0.006 & 0.142 & 0.603 & 1.428 & 0.734 \\
DSENT & 0.000 & 0.000 & 0.532 & 1.000 & 1.000 & 1.000 & 0.499 \\
CSENT & -1.280 & -0.310 & 0.074 & 0.020 & 0.501 & 2.189 & 0.699 \\
SUE & -3.710 & -0.065 & 0.098 & 0.002 & 0.200 & 4.107 & 1.186 \\
SAR60 & -0.532 & -0.120 & -0.009 & -0.017 & 0.094 & 0.614 & 0.199 \\
MAR60 & -0.436 & -0.111 & 0.009 & -0.009 & 0.111 & 0.642 & 0.197 \\
SIZE & 23.150 & 25.133 & 26.502 & 26.251 & 27.797 & 30.787 & 1.832 \\
VOLM & 6.498 & 9.987 & 11.203 & 11.319 & 12.519 & 15.125 & 1.864 \\
VALUE & 17.483 & 21.101 & 23.103 & 22.976 & 24.832 & 30.259 & 2.828 \\
ROA & -0.217 & 0.011 & 0.038 & 0.036 & 0.067 & 0.196 & 0.127 \\
MTB & 0.217 & 0.610 & 1.351 & 0.963 & 1.561 & 6.949 & 1.351 \\
LEVER & 0.035 & 0.265 & 0.423 & 0.433 & 0.567 & 0.842 & 0.195 \\
FOLLOW & 0.000 & 0.000 & 4.415 & 1.000 & 5.000 & 27.000 & 6.612 \\
FOR(\%) & 0.000 & 1.890 & 13.258 & 7.640 & 20.060 & 63.680 & 14.956 \\
BETA & 0.006 & 0.542 & 0.830 & 0.805 & 1.095 & 1.754 & 0.479 \\
VOLATI & 18.772 & 33.341 & 45.539 & 42.397 & 54.469 & 96.385 & 20.455 \\
BIG4 & 0.000 & 1.000 & 0.752 & 1.000 & 1.000 & 1.000 & 0.432 \\
\hline
\end{tabular}

Note: Please refer to the variable definitions in research model 1.

Next, Table 3 represents the results of the correlation analysis for the main variables. These results show that unexpected earnings (SUE) and cumulative abnormal returns (SAR60 and MAR60) are highly correlated ( $\varrho$ of Spearman $=0.089$ and 0.095 , respectively), indicating that there exists a drift in 
stock price related to earnings surprise (shock). Note that both market sentiment variables, PSENT and ASENT, are negatively correlated with size-adjusted abnormal returns (MAR60) and not correlated with market-adjusted abnormal returns (MAR60). However, our key variables, DSENT and CSENT (i.e., the change in market sentiment variables), are positively associated with MAR60 but negatively associated with SAR60. The correlation of Market sentiment variables, PSENT and ASENT, and SUE is not significant, except that ASENT is negatively correlated with SUE. Similarly, both DSENT and CSENT are not correlated with SUE.

Table 3. Correlations Analysis Results ( $\mathrm{N}=15,315)$.

\begin{tabular}{cccccccc}
\hline & SUE & PSENT & ASENT & DSENT & CSENT & SAR60 & Mar-60 \\
\hline SUE & & 0.009 & 0.003 & -0.004 & -0.008 & 0.082 & 0.075 \\
& & $(0.242)$ & $(0.743)$ & $(0.620)$ & $(0.338)$ & $(<0.000)$ & $(<0.000)$ \\
PSENT & 0.004 & & 0.296 & -0.584 & -0.483 & -0.001 & -0.058 \\
& $(0.622)$ & & $(<0.000)$ & $(<0.000)$ & $(<0.000)$ & $(0.894)$ & $(<0.000)$ \\
ASENT & -0.013 & 0.247 & & 0.014 & 0.221 & 0.011 & -0.022 \\
& $(0.095)$ & $(<0.000)$ & & $(0.083)$ & $(0.000)$ & $(0.190)$ & $(0.007)$ \\
DSENT & -0.001 & -0.568 & -0.012 & & 0.781 & -0.026 & 0.024 \\
& $(0.933)$ & $(<0.000)$ & $(0.141)$ & & $(<0.000)$ & $(0.001)$ & $(0.003)$ \\
CSENT & 0.004 & -0.445 & 0.158 & 0.865 & & -0.01 & 0.045 \\
& $(0.662)$ & $(<0.000)$ & $(<0.000)$ & $(<0.0001)$ & & $(0.239)$ & $(<0.000)$ \\
SAR60 & 0.089 & 0.008 & 0.003 & -0.031 & -0.029 & & 0.355 \\
& $(<0.000)$ & $(0.344)$ & $(0.683)$ & $(0.000)$ & $(0.000)$ & & $(<0.000)$ \\
Mar-60 & 0.095 & -0.051 & -0.018 & 0.016 & 0.027 & 0.403 & \\
& $(<0.000)$ & $(<0.000)$ & $(0.026)$ & $(0.044)$ & $(0.001)$ & $(<0.000)$ & \\
\hline
\end{tabular}

Note: Please refer to the variable definitions in research model 1. The Pearson correlation coefficients are indicated on the right of the empty diagonal and Spearman correlation coefficients are on the left. The figures in parentheses are $p$-values.

Overall, the results of the correlation analysis between the change in market sentiment and subsequent abnormal returns following earnings announcements are mixed. However, the results are distinguishable from those on the level of market sentiment, indicating that the effect of the change in market sentiment on subsequent abnormal returns does not subsume the effect of the level of market sentiment at a specific point in time. To verify our hypothesis in the next section, we conducted a regression analysis on the model controlling for a variety of factors affecting abnormal returns.

\subsection{Regression Analysis Results}

Table 4 provides the regression results for our hypothesis regarding the effects of changes in market sentiment. We measured changes in market sentiment in two ways, as DSENT and CSENT. Where, DSENT denotes the indicator variable on whether market sentiment increases over two quarters $(t-1$ and $t)$ and CSENT denotes the change value in the market sentiment over two quarters $(t-1$ and $t$ ). Our interesting variables are the interaction terms, DSUE*DSENT in Panel A and DSUE*CSENT in Panel B. The coefficient of DSUE*DSENT on size-adjusted abnormal returns (SAR60) is positive and significant at the $10 \%$ level $(0.0168$, t-statistic $=1.85)$. Moreover, the coefficient of DSUE*CSENT on SAR60 is also significantly positive at the $1 \%$ level $(0.0196$, $t$-statistic $=2.84)$. These results are more robust to the estimation by market-adjusted abnormal returns (MAR60). Specifically, the coefficients of DSUE*DSENT on SAR60 or MAR60 are all positive and significant at the $1 \%$ level ( $\mathrm{t}$-statistic $=4.10$ and 3.66 , respectively).

Notably, the results hold after controlling for the effect of market sentiment at a specific point in time, prior-sentiment (PSENT) and following-sentiment (ASENT).

Since the coefficients of DSUE are positive and significant, these results indicate that the magnitude of PEAD incrementally increases with an (upward) change in the market sentiment, consistent with our hypothesis. Overall, our findings imply that the incremental increase in the magnitude of PEAD is attributable to investors' inertia, which leads them to underreact to earnings information, in line with 
the direction of change in market sentiment. It is not the effect of mispricing on the market sentiment at a specific point in time.

Table 4. The Change in Market sentiment and Post-Earnings Announcement Drift (PEAD).

\begin{tabular}{|c|c|c|c|c|c|c|}
\hline \multicolumn{7}{|c|}{ Panel A: Increase in Market Sentiment between Pre- and Post-Announcement (DSENT) } \\
\hline \multirow[t]{2}{*}{ Variables } & \multicolumn{3}{|c|}{ SAR60 } & \multicolumn{3}{|c|}{ MAR60 } \\
\hline & Coefficent & \multicolumn{2}{|c|}{ t-Value } & \multirow{2}{*}{$\begin{array}{c}\text { Coefficient } \\
-0.0492\end{array}$} & \multicolumn{2}{|c|}{ t-Value } \\
\hline Const. & -0.0903 & -5.52 & $* * *$ & & -3.46 & \\
\hline DSUE & 0.0391 & 5.86 & $* * *$ & 0.0337 & 5.04 & $* * *$ \\
\hline DSUE* DSENT $_{t}$ & 0.0168 & 1.85 & * & 0.0420 & 4.10 & $* * *$ \\
\hline DSENT & -0.0324 & -4.76 & $* * *$ & -0.0383 & -5.45 & \\
\hline PSENT $_{\mathrm{t}}$ & -0.0160 & -3.74 & $* * *$ & -0.0264 & -6.77 & $* * *$ \\
\hline ASENT & 0.0103 & 3.39 & $* * *$ & 0.0001 & 0.03 & \\
\hline SIZE & 0.0382 & 3.63 & $* * *$ & -0.0346 & -4.18 & $* * *$ \\
\hline VOLM & 0.0275 & 3.08 & $* * *$ & 0.0141 & 2.06 & $* *$ \\
\hline VALUE & -0.0249 & -2.24 & $* *$ & -0.0069 & -0.76 & \\
\hline ROA & 0.0232 & 3.56 & $* * *$ & 0.0249 & 4.56 & $* * *$ \\
\hline MTB & -0.0184 & -2.67 & $* * *$ & 0.0121 & 2.26 & $* *$ \\
\hline LEVER & 0.0307 & 3.94 & $* * *$ & 0.0571 & 7.94 & $* * *$ \\
\hline FOLLOW & 0.0325 & 3.70 & $* * *$ & -0.0156 & -2.08 & $* *$ \\
\hline FOR & -0.0121 & -1.69 & $*$ & -0.0125 & -2.07 & $* *$ \\
\hline BETA & -0.0040 & -0.59 & & -0.0177 & -3.11 & $* * *$ \\
\hline VOLATI & 0.0030 & 0.40 & & 0.0199 & 3.02 & $* * *$ \\
\hline BIG4 & -0.0009 & -0.21 & & -0.0025 & -0.69 & \\
\hline$\sum \mathrm{YR}$ & & & & & uded & \\
\hline EIndustry & & & & & uded & \\
\hline ADJ. $R^{2}$ & & & & & $68 \%$ & \\
\hline Obs. & & & & & ,315 & \\
\hline Firm Clust. SE & & & & & Yes & \\
\hline \multicolumn{7}{|c|}{ Panel B: Increase in Market Sentiment between Pre- and Post-Announcement (CSENT) } \\
\hline \multirow[t]{2}{*}{ Variables } & \multicolumn{3}{|c|}{ SAR60 } & \multicolumn{3}{|c|}{ MAR60 } \\
\hline & \multicolumn{2}{|l|}{ Coefficent } & t-Value & Coefficent & \multicolumn{2}{|c|}{ t-Value } \\
\hline Const. & -0.1018 & -6.34 & $* * *$ & -0.0734 & -5.27 & *** \\
\hline DSUE & 0.0465 & 9.07 & $* * *$ & 0.0540 & 11.35 & $* * *$ \\
\hline DSUE*CSENT & 0.0196 & 2.84 & $* * *$ & 0.0274 & 3.66 & $* * *$ \\
\hline CSENT & -0.0175 & -3.66 & $* * *$ & -0.0119 & -2.44 & $* *$ \\
\hline PSENT $_{\mathrm{t}}$ & -0.0070 & -1.93 & $*$ & -0.0161 & -4.71 & $* * *$ \\
\hline SIZE & 0.0382 & 3.63 & $* * *$ & -0.0342 & -4.16 & $* * *$ \\
\hline VOLM & 0.0276 & 3.10 & $* * *$ & 0.0143 & 2.09 & $* *$ \\
\hline VALUE & -0.0250 & -2.26 & $* *$ & -0.0072 & -0.79 & \\
\hline ROA & 0.0233 & 3.58 & $* * *$ & 0.0251 & 4.60 & $* * *$ \\
\hline MTB & -0.0185 & -2.68 & $* * *$ & 0.0118 & 2.21 & $* *$ \\
\hline LEVER & 0.0308 & 3.96 & $* * *$ & 0.0569 & 7.92 & $* * *$ \\
\hline FOLLOW & 0.0325 & 3.71 & $* * *$ & -0.0154 & -2.04 & $* *$ \\
\hline FOR & -0.0123 & -1.73 & $*$ & -0.0129 & -2.14 & $* *$ \\
\hline BETA & -0.0041 & -0.61 & & -0.0177 & -3.12 & $* * *$ \\
\hline VOLATI & 0.0031 & 0.40 & & 0.0199 & 3.02 & $* * *$ \\
\hline BIG4 & -0.0008 & -0.17 & & -0.0024 & -0.69 & \\
\hline$\sum \mathrm{YR}$ & \multicolumn{2}{|c|}{ Included } & & \multicolumn{3}{|c|}{ Included } \\
\hline$\sum$ Industry & \multicolumn{2}{|c|}{ Included } & & \multicolumn{3}{|c|}{ Included } \\
\hline ADJ. $R^{2}$ & \multicolumn{2}{|c|}{$2.56 \%$} & & \multicolumn{3}{|c|}{$3.68 \%$} \\
\hline Obs. & & & & & ,315 & \\
\hline Firm Clust. SE & & & & & Yes & \\
\hline
\end{tabular}

Note: Please refer to the variable definitions in research model 1 . The notation ${ }^{*}, * *$, and ${ }^{* * *}$ represent significance level at the $10 \%, 5 \%$, and $1 \%$, respectively.

Prior to the adjustment of such a potential problem through the statistical method, we checked the degree of heteroscedasticity and serial-autocorrelation by using the Durbin Watson [51] test. 
The DW value of the Durbin Watson test ranges from 0 to 4 . The value near 0 implies positive serial autocorrelation and that near 4 implies negative serial correlation. [52,53]. The test results on our main hypothesis in Table 4 show that DW-statistics present the value between 1 and $2(1.884,1.881)$, indicating the existence of slightly positive auto-correlation among residuals. Finally, to control some estimation biases since our data, as panel data, entail the cross-sectional or time-serial correlation in error term, we include dummy variables for year and industry in the model. Furthermore, all regression models use t-statistics based on robust standard errors clustered at firm level [48].

\subsection{Portfolio Drift Test}

While the regression analysis results provide the effect of the change in market sentiment on the stock price drift, a portfolio drift test in this section suggests the economic significance of the accounting earnings information (i.e., SUE) and mispricing due to investors' inertia under the change in market sentiment. Table 5 represents the average abnormal returns on each portfolio, conditional on both SUE quintiles and the change in the market sentiment state (Upward Shift, Downward Shift). Upward (Downward) shifts happen when the market sentiment rises (falls) between the current and the previous quarter. Panel A presents the test results based on the cumulative size-adjusted abnormal returns (SAR60) and Panel B presents the test results based on the cumulative market-adjusted abnormal returns (MAR60).

Table 5. Portfolio Returns for Standardized Unexpected Earnings (SUE) across Change of Market Sentiment.

\begin{tabular}{|c|c|c|c|c|c|c|}
\hline \multicolumn{7}{|c|}{ Panel A: Cumulative Size-Adjusted Abnormal Returns (SAR60) } \\
\hline \multirow[b]{2}{*}{ SUE Quintiles } & \multirow{2}{*}{\multicolumn{2}{|c|}{ Unconditional }} & \multicolumn{2}{|c|}{ Downward Shift } & \multicolumn{2}{|c|}{ Upward Shift } \\
\hline & & & SAR & t-Value & SAR & t-Value \\
\hline SUE1 & $-4.01 \%$ & -10.43 & $-2.85 \%$ & -5.37 & $-5.02 \%$ & -9.13 \\
\hline SUE2 & $-1.43 \%$ & -4.56 & $-0.56 \%$ & -1.36 & $-2.29 \%$ & -4.82 \\
\hline SUE3 & $-0.30 \%$ & -1.02 & $-1.22 \%$ & -2.91 & $0.37 \%$ & 0.90 \\
\hline SUE4 & $0.30 \%$ & 0.88 & $0.54 \%$ & 1.19 & $0.06 \%$ & 0.12 \\
\hline SUE5 & $0.71 \%$ & 1.90 & $1.94 \%$ & 3.45 & $-0.33 \%$ & -0.65 \\
\hline 5-1 & $4.72 \%$ & 8.79 & $4.79 \%$ & 6.19 & $4.69 \%$ & 6.30 \\
\hline \multicolumn{7}{|c|}{ Panel B: Cumulative Market-Adjusted Abnormal Returns (MAR60) } \\
\hline & & & \multicolumn{2}{|c|}{ Downward Shift } & \multicolumn{2}{|c|}{ Upward Shift } \\
\hline SUE Quintiles & \multicolumn{2}{|c|}{ Unconditional } & MAR & t-Value & MAR & t-Value \\
\hline SUE1 & $-1.59 \%$ & -4.36 & $-0.92 \%$ & -1.80 & $-2.18 \%$ & -4.20 \\
\hline SUE2 & $-0.24 \%$ & -0.77 & $-0.13 \%$ & -0.31 & $-0.35 \%$ & -0.76 \\
\hline SUE3 & $0.43 \%$ & 1.39 & $-1.86 \%$ & -4.26 & $2.11 \%$ & 4.86 \\
\hline SUE4 & $2.56 \%$ & 7.29 & $2.04 \%$ & 4.26 & $3.09 \%$ & 5.99 \\
\hline SUE5 & $3.21 \%$ & 8.89 & $2.56 \%$ & 5.00 & $3.75 \%$ & 7.42 \\
\hline $5-1$ & $4.80 \%$ & 9.35 & $3.49 \%$ & 4.81 & $6.93 \%$ & 8.19 \\
\hline
\end{tabular}

Note: This table represents the average abnormal returns on each portfolio conditioned on both SUE quintiles and the change in the market sentiment state (Upward Shift, Downward Shift). SUE denotes the standardized unexpected earnings calculated using a time series forecast of earnings. Market sentiment is the Korean market sentiment index suggested by Kim and Byun [13]. Upward (Downward) shift denotes when the market sentiment rises (falls) between the current and the previous quarter. The abnormal returns, SAR60 and MAR60, are size-adjusted(market-adjusted) cumulative abnormal returns over each trading day from the day after the earnings announcement date (day 0 ) for quarter $t$. Hedge returns for a portfolio of 5-1 indicates the abnormal returns from investment strategy that longs the highest portfolio (SUE5) and shorts the lowest portfolio (SUE1). Please refer to the variable definitions in research model 1.

Given that PEAD shows the magnitude of the gap between cumulative abnormal returns on positive and on negative unexpected earnings, we predict that hedge returns for the portfolio of 5-1, which is the abnormal returns from the investment strategy that longs the highest portfolio (SUE5) and shorts the lowest portfolio (SUE1), is higher in the Upward Shift group than in the Downward Shift 
group. Consistent with the regression analysis results but only in the test based on market-adjusted abnormal returns (panel B), the result shows the hedge returns for a portfolio of 5-1 when the market sentiment shifts upwardly are higher than those when the market sentiment shifts downwardly. Specifically, hedge returns for stocks in a portfolio with an Upward Shift are $6.93 \%$ (t-statistic $=8.19$ ) of MAR60. It is larger than the hedge returns with a Downward Shift (3.49\% of MAR60) and those with market sentiment-unconditioned portfolio $(4.80 \%$ (t-statistic $=9.35)$ of MAR60). These results indicate that the extent of PEAD systematically differs by the change in market sentiment and increases with the upward change in market sentiment. However, such an argument is not evident in size-adjusted abnormal return (SAR60) - based test in Panel A, because the higher PEAD with upward shift of market sentiment occurs only in the two lowest SUEs and by and large, is not significant in high SUEs. Considering the portfolio drift is testable regardless of any other factors on PEAD, this result is acceptable to such a degree that our hypothesis is partially supported. Finally, our findings suggest that understanding accounting-based earnings information beforehand is important in order to avoid suffering from mispricing due to investor inertia on market sentiment.

\subsection{Additional Test: Asymmetric PEAD}

According to Mian and Sankaraguruswamy [44], market sentiment differently affects the magnitude of PEAD by the level of unexpected earnings. They argue that when market sentiment is high, investors overreact to positive unexpected earnings but underreact to negative unexpected earnings. By contrast, when market sentiment is low, investors overreact (underreact) to the negative (positive) unexpected earnings. Accordingly, we expect the effect of the change in market sentiment on the magnitude of PEAD to also be asymmetric by the level of unexpected earnings. However, the results show that PEAD due to investor inertia is asymmetric by the level of unexpected earnings. We include the changes in the market sentiment conditional on positive and negative unexpected earnings as independent variables and regress them on subsequent abnormal returns following an earnings announcement (i.e., SAR60 and MAR60).

$$
\begin{aligned}
\text { AR60 }_{i, t} & =\beta_{0}+\beta_{1} \text { DSUE }(\text { Pos })_{i, t}+\beta_{2} D S U E(N e g)_{i, t} \\
& +\beta_{3} D S U E(P o s)_{i, t} \times C H S E N T_{t} \\
& +\beta_{4} \text { DSUE }(N e g)_{i, t} \times C H S E N T_{t}+\beta_{5} \text { CHSENT }_{t} \\
& +\beta_{6} \text { PSENT }_{t}+\beta_{7} \text { ASENT } \\
& + \text { Fixt }+ \text { Contol Variables } \\
& \text { Effect }+\varepsilon_{i, t}
\end{aligned}
$$

The results are presented in Table 6. Panel A and Panel B represent the regression results on DSENT and CSENT, respectively. The coefficients of positive unexpected earnings (DSUE(Pos)) and the interaction terms of market sentiment conditional on the positive unexpected earnings (DSUE(Pos)*DSENT or DSUE(Pos)*CSENT) are all statistically significant on the abnormal returns (SAR60 and MAR60). While the coefficient of the negative unexpected earnings (DSUE(Neg)) and interaction terms of market sentiment conditional on the negative unexpected earnings (DSUE(Neg)* DSENT or DSUE(Neg)*CSENT) are not significant. Only the terms, DSUE(Neg) and DSUE(Neg)*CSENT, regressed on MAR60 are significant, as presented in panel B. Collectively, the effect of the change in market sentiment on PEAD varies with the direction of unexpected earnings, but the significance of those results is weak. This implies that stock price drift due to underreaction to earnings information with regard to the investor inertia is relatively dominant for positive unexpected earnings. 
Table 6. Additional Test: Asymmetric PEAD.

\begin{tabular}{|c|c|c|c|c|c|c|}
\hline \multicolumn{7}{|c|}{ Panel A: Upward Shift in Market Sentiment (DSENT) } \\
\hline \multirow[t]{2}{*}{ Variables } & \multicolumn{3}{|c|}{ SAR60 } & \multicolumn{3}{|c|}{ MAR60 } \\
\hline & Coefficient & t-Value & & Coefficient & t-Value & \\
\hline Const. & -0.0845 & -5.22 & $* * *$ & -0.0440 & -3.05 & *** \\
\hline DSUE(Pos) & 0.0344 & 4.78 & $* * *$ & 0.0304 & 4.31 & *** \\
\hline DSUE(Neg) & 0.0049 & 0.27 & & 0.0067 & 0.37 & \\
\hline DSUE(Pos)*DSENT & 0.0162 & 1.66 & * & 0.0440 & 4.13 & *** \\
\hline DSUE(Neg)*DSENT & 0.0146 & 0.55 & & 0.0585 & 2.26 & $* *$ \\
\hline DSENT & -0.0320 & -4.08 & $* * *$ & -0.0407 & -5.15 & $* * *$ \\
\hline PSENT & -0.0160 & -3.74 & $* * *$ & -0.0263 & -6.76 & $* * *$ \\
\hline \multirow[t]{2}{*}{ ASENT } & 0.0103 & 3.40 & $* * *$ & 0.0002 & 0.05 & \\
\hline & \multicolumn{3}{|c|}{ Control variables } & \multicolumn{3}{|c|}{ Control variables } \\
\hline$\sum \mathrm{YR}$ & \multicolumn{3}{|c|}{ Included } & \multicolumn{3}{|c|}{ Included } \\
\hline$\sum$ Industry & \multicolumn{3}{|c|}{ Included } & \multicolumn{3}{|c|}{ Included } \\
\hline ADJ. $R^{2}$ & \multicolumn{3}{|c|}{$2.75 \%$} & \multicolumn{3}{|c|}{$3.65 \%$} \\
\hline Obs. & \multicolumn{3}{|c|}{15,315} & \multicolumn{3}{|c|}{15,315} \\
\hline Firm Clust.SE & \multicolumn{3}{|c|}{ Yes } & \multicolumn{3}{|c|}{ Yes } \\
\hline \multicolumn{7}{|c|}{ Panel B: Upward Shift in Market Sentiment (CSENT) } \\
\hline \multirow[t]{2}{*}{ Variables } & \multicolumn{3}{|c|}{ SAR60 } & \multicolumn{3}{|c|}{ MAR60 } \\
\hline & Coefficient & t-Value & & Coefficient & t-Value & \\
\hline Const. & -0.0993 & -6.23 & $* * *$ & -0.0686 & -4.89 & *** \\
\hline DSUE(Pos) & 0.0416 & 7.35 & $* * *$ & 0.0517 & 10.12 & $* * *$ \\
\hline DSUE(Neg) & 0.0112 & 0.77 & & 0.0349 & 2.65 & $* * *$ \\
\hline DSUE(Pos)*CSENT & 0.0191 & 2.54 & ** & 0.0282 & 3.61 & $* * *$ \\
\hline DSUE(Neg)*CSENT & 0.0164 & 0.82 & & 0.0344 & 1.78 & * \\
\hline CSENT & -0.0133 & -2.43 & $* *$ & -0.0027 & -0.50 & \\
\hline \multirow[t]{2}{*}{ ASENT } & 0.0071 & & $* *$ & -0.0060 & -2.15 & $* *$ \\
\hline & \multicolumn{3}{|c|}{ Control variables } & \multicolumn{3}{|c|}{ Control variables } \\
\hline$\sum \mathrm{YR}$ & \multicolumn{3}{|c|}{ Included } & \multicolumn{3}{|c|}{ Included } \\
\hline$\sum$ Industry & \multicolumn{3}{|c|}{ Included } & \multicolumn{3}{|c|}{ Included } \\
\hline ADJ. $R^{2}$ & \multicolumn{3}{|c|}{$2.62 \%$} & & $4 \%$ & \\
\hline Obs. & & 315 & & & 315 & \\
\hline Firm Clust.SE & & & & & es & \\
\hline
\end{tabular}

Note: Please refer to the variable definitions in research model 1. The notation ${ }^{*}, * *$ and ${ }^{* * *}$ represent significance level at the $10 \%, 5 \%$, and $1 \%$, respectively.

To confirm this asymmetric PEAD on unexpected earnings, we examine the stock returns for each cumulative trading day following the earnings announcement date with a 10-day interval. In this test, we use portfolios with the highest and the lowest SUE to more clearly identify the relation between unexpected earnings and the change in market sentiment. As denoted in panel B of Table 7, the market-adjusted abnormal returns only on positive unexpected earnings (SUE5) are incrementally high for portfolios with an upward change in market sentiment, whereas those of negative unexpected earnings (SUE1) does not show higher drift magnitude due to the change in market sentiment. For 60 trading days following the earnings announcement, cumulative market-adjusted returns (MAR60) on SUE5 increase to $3.75 \%$ from $3.21 \%$ when conditional on an upward shift in the market sentiment, indicating that the upward change in market sentiment affects the magnitude of PEAD on positive unexpected earnings. However, for our sample, cumulative size-adjusted returns on unexpected earnings (SUEs) seem to be unconnected with PEAD due to a shift in market sentiment. These results are all but in line with those of the regression analysis in Panel A of Table 6, which shows the estimates of unexpected earnings (SUEs) and the interaction terms of DSENT are not significant or statistically weak. Overall, the results support in part the argument that the magnitude of PEAD on earnings information with regard to the investor inertia exists asymmetrically with the direction of unexpected earnings. 
Table 7. Cumulative Abnormal Returns across Positive SUE and Negative SUE by the Change of Market Sentiment.

\begin{tabular}{|c|c|c|c|c|c|c|}
\hline \multicolumn{7}{|c|}{ Panel A: SAR60 } \\
\hline & \multicolumn{6}{|c|}{ Cumulative Trading Days Following Earnings Announcement Date } \\
\hline & 10 & 20 & 30 & 40 & 50 & 60 \\
\hline SUE5/Upward & $0.88 \%$ & $0.79 \%$ & $0.60 \%$ & $0.29 \%$ & $0.49 \%$ & $-0.33 \%$ \\
\hline SUE5 & $0.47 \%$ & $0.64 \%$ & $0.76 \%$ & $0.70 \%$ & $1.72 \%$ & $0.71 \%$ \\
\hline SUE1 & $-0.72 \%$ & $-1.08 \%$ & $-1.68 \%$ & $-2.64 \%$ & $-2.75 \%$ & $-4.01 \%$ \\
\hline SUE1/Downward & $-0.93 \%$ & $-1.16 \%$ & $-1.56 \%$ & $-1.88 \%$ & $-2.12 \%$ & $-2.85 \%$ \\
\hline \multicolumn{7}{|c|}{ Panel B: MAR60 } \\
\hline SUE5/Upward & $0.81 \%$ & $1.67 \%$ & $2.64 \%$ & $3.17 \%$ & $3.96 \%$ & $3.75 \%$ \\
\hline SUE5 & $1.17 \%$ & $1.82 \%$ & $2.42 \%$ & $2.87 \%$ & $4.91 \%$ & $3.21 \%$ \\
\hline SUE1 & $0.64 \%$ & $0.05 \%$ & $0.01 \%$ & $-0.25 \%$ & $-0.36 \%$ & $-1.59 \%$ \\
\hline SUE1/Downward & $1.32 \%$ & $0.07 \%$ & $0.24 \%$ & $0.05 \%$ & $-0.17 \%$ & $-0.92 \%$ \\
\hline \multicolumn{7}{|c|}{$\begin{array}{l}\text { Note: This table represents the cumulative abnormal returns on each portfolio, conditional on both the highest } \\
\text { (lowest) SUE of quintiles and the change of market sentiment state (Upward Shift, Downward Shift). SUE denotes } \\
\text { the standardized unexpected earnings calculated using a time series forecast of earnings. Market sentiment is the } \\
\text { Korean market sentiment index suggested by Kim and Byun. Upward (Downward) shift denotes when the market } \\
\text { sentiment rises (falls) between the current and the previous quarter. The abnormal returns, SAR60 and MAR } 60 \\
\text { are size-adjusted (market-adjusted) cumulative abnormal returns over each trading day from the day after the } \\
\text { earnings announcement date (day 0) for quarter t. }\end{array}$} \\
\hline
\end{tabular}

\subsection{Additional Test: The Effect of Prior-Sentiment and Following-Sentiment on PEAD}

This section discusses whether the extent of the PEAD is systematically different by the market sentiment during pre- and post-earnings announcement periods. Since the change in market sentiment is measured as the difference between prior-sentiment level and following-sentiment level, it is possible that the magnitude of the drift in stock price by the change in market sentiment subsumes the independent effect of prior-sentiment or following-sentiment. Moreover, previous studies have documented the market sentiment effect on stock reaction or long-term stock returns in terms of prior-sentiment, as delineated in Section 2.

However, there remains a question of whether investors' optimism due to high market sentiment following an earnings announcement (i.e., following-sentiment) significantly influences stock price drift regardless of the level of prior-sentiment. If investors pass over the information implied in prior-sentiment or prior mispricing and thus naively form their belief based on the following-sentiment when they predict future performance, then their higher optimism due to high following-sentiment may cause the higher magnitude of stock price drift.

Thus, we conjecture that the relation between the magnitude of PEAD and market sentiment varies with not only the prior-sentiment but also the following-sentiment. More specifically, we predict that while the magnitude of PEAD decreases with prior-sentiment, the magnitude of PEAD increases with following-sentiment. To test our conjecture, we implement the following regression models. First, we test the incremental effect of prior-sentiment (PSENT) on abnormal returns while controlling for following-sentiment (ASENT) and the other determinants of PEAD:

$$
\begin{aligned}
\text { AR60 }_{i, t} & =\beta_{0}+\beta_{1} D S U E_{i, t}+\beta_{2} D_{S S U E_{i, t}} \times \text { PSENT }_{t}+\beta_{3} \text { PSENT }_{t} \\
& +\beta_{4} A S E N T_{t}+\text { Control Variables }+\sum \text { Year Effect } \\
& +\varepsilon_{i, t}
\end{aligned}
$$

Next, we also test the incremental effect of following-sentiment (ASENT) on abnormal returns while controlling for prior-sentiment (PSENT) and the other determinants of PEAD: 


$$
\begin{aligned}
\text { AR60 }_{i, t} & =\beta_{0}+\beta_{1} \text { DSUE }_{i, t}+\beta_{2} \text { DSUE }_{i, t} \times \text { ASENT }_{t}+\beta_{3} \text { PSENT }_{t} \\
& +\beta_{4} \text { ASENT }_{t}+\text { Control Variables }+\sum \text { Year Effect } \\
& +\varepsilon_{i, t}
\end{aligned}
$$

We intersect the unexpected earnings variable (DSUE) with the market sentiment variables (PSENT or ASENT) to capture the incremental effect of market sentiment on PEAD. If the state of market sentiment for pre (post)-earnings announcement periods incrementally affects PEAD, the coefficient of DSUE*PSENT is significantly negative, and that of DSUE*ASENT is significantly positive.

Table 8 presents the regression results. Panel A reports the results for the effect of prior-sentiment. The high prior-sentiment conditional on DSUE has mitigating effects on abnormal returns, as denoted by the significant negative coefficient of DSUE*PSENT $(-0.0299$, t-statistic $=-4.37)$, indicating that prior-sentiment lowers the magnitude of PEAD. On the contrary to this, for the following-sentiment in Panel B, DSUE*ASENT is positive and statistically significant $(0.0140$, $t$-statistic $=2.20)$. The test results in Panel B are also similar with those in Panel A. These results imply that only following-sentiment is

\begin{tabular}{|c|c|c|c|c|c|c|}
\hline \multicolumn{7}{|c|}{ Panel A: Market Sentiment for Pre-Announcement (PSENT) } \\
\hline \multirow[t]{2}{*}{ Variables } & \multicolumn{3}{|c|}{ SAR60 } & \multicolumn{3}{|c|}{ MAR60 } \\
\hline & Coefficient & \multicolumn{2}{|c|}{ t-Value } & \multirow{2}{*}{$\begin{array}{c}\text { Coefficient } \\
-0.0680\end{array}$} & \multicolumn{2}{|c|}{ t-Value } \\
\hline Const. & -0.1078 & -6.75 & $* * *$ & & -4.88 & $* * *$ \\
\hline DSUE & 0.0420 & 8.16 & $* * *$ & 0.0505 & 10.34 & $* * *$ \\
\hline DSUE*PSENT & -0.0299 & -4.37 & $* * *$ & -0.0291 & -4.12 & $* * *$ \\
\hline PSENT & 0.0121 & 2.63 & $* * *$ & -0.0024 & -0.53 & \\
\hline \multirow[t]{2}{*}{ ASENT } & 0.0071 & 2.47 & $* *$ & -0.0022 & -0.77 & \\
\hline & \multicolumn{3}{|c|}{ Control Variables } & \multicolumn{3}{|c|}{ Control Variables } \\
\hline$\sum \mathrm{YR}$ & \multicolumn{3}{|c|}{ Included } & \multicolumn{3}{|c|}{ Included } \\
\hline ADJ. $R^{2}$ & \multicolumn{3}{|c|}{$2.62 \%$} & \multicolumn{3}{|c|}{$3.53 \%$} \\
\hline Obs. & \multicolumn{3}{|c|}{15,315} & \multicolumn{3}{|c|}{15,315} \\
\hline Firm Clust. SE & \multicolumn{3}{|c|}{ Yes } & \multicolumn{3}{|c|}{ Yes } \\
\hline
\end{tabular}
an influential factor on PEAD and not prior-sentiment.

\begin{tabular}{|c|c|c|c|c|c|c|}
\hline \multicolumn{7}{|c|}{ Panel B: Market Sentiment for Post-Announcement (ASENT) } \\
\hline \multirow[t]{2}{*}{ Variables } & \multicolumn{3}{|c|}{ SAR60 } & \multicolumn{3}{|c|}{ MAR60 } \\
\hline & Coefficient & t-Value & & Coefficient & t-Value & \\
\hline Const. & -0.1109 & -6.89 & $* * *$ & -0.0710 & -5.12 & $* * *$ \\
\hline DSUE & 0.0480 & 9.33 & $* * *$ & 0.0564 & 11.79 & $* * *$ \\
\hline DSUE*ASENT & 0.0140 & 2.20 & $* *$ & 0.0149 & 2.22 & ** \\
\hline PSENT & -0.0029 & -0.91 & & -0.0169 & -5.73 & $* * *$ \\
\hline \multirow[t]{2}{*}{ ASENT } & 0.0001 & & & -0.0096 & -2.12 & $* *$ \\
\hline & \multicolumn{3}{|c|}{ Control Variables } & \multicolumn{3}{|c|}{ Control Variables } \\
\hline$\sum \mathrm{YR}$ & \multicolumn{3}{|c|}{ Included } & \multicolumn{3}{|c|}{ Included } \\
\hline ADJ. $R^{2}$ & \multicolumn{3}{|c|}{$2.54 \%$} & \multicolumn{3}{|c|}{$3.45 \%$} \\
\hline Obs. & \multicolumn{3}{|c|}{15,315} & \multicolumn{3}{|c|}{15,315} \\
\hline Firm Clust. SE & \multicolumn{3}{|c|}{ Yes } & \multicolumn{3}{|c|}{ Yes } \\
\hline
\end{tabular}

Table 8. Additional Analysis: the effect of prior-sentiment and following-sentiment on PEAD.

Note: Please refer to the variable definitions in research model 1 . The notation $* * *$, and ${ }^{* * *}$ represent significance level at the $10 \%, 5 \%$, and $1 \%$, respectively. All regression models use t-statistics based on robust standard errors clustered at the firm [48] and include year fixed effects.

\subsection{Additional Test: The Effect of the Change in Market Sentiment on ERC(Earnings Response Coefficient)}

Since PEAD is attributed to the investors not having a sufficient reaction to earnings news at the announcement date, in this section we examine the earnings response coefficient by the change in market sentiment. If investor inertia under the market sentiment change truly affects the extent 
of the stock price response, investors should respond less to earnings information when the market sentiment is rising continuously around an earnings announcement period.

To address our conjecture, we conduct a regression model as follows.

$$
\begin{aligned}
A_{R 3_{i, t}} & =\beta_{0}+\beta_{1} D_{S U E_{i, t}}+\beta_{2} D_{S U E} E_{i, t} \times \text { CHSENT }_{t}+\beta_{3} \text { CHSENT }_{t} \\
& +\beta_{4} \text { PSENT }_{t}+\beta_{5} \text { ASENT }_{t}+\text { control variables } \\
& +\sum \text { Year Effect }+\varepsilon_{i, t}
\end{aligned}
$$

where, AR3 represents cumulative size-adjusted abnormal returns $(\operatorname{SAR}(-1,+1)$ measured over the three trading days around the quarterly earnings announcement date (0). Other variables are identical to the main models in this study. Still, the interaction term (DSUE*CHSENT) captures the incremental effects of the change in market sentiment between pre- and post-earnings announcement periods on abnormal returns, conditional on the SUE decile rankings. If investors' response to earnings information lowers due to investor inertia when the market sentiment upwardly changes, we expect the slope coefficient of the interaction term to be significantly negative.

Table 9 provides evidence that the change in market sentiment has no incremental effect on stock price reaction around the earnings announcement period. As presented, the coefficients of DSUE*CHSENT are negative but not statistically significant, while the coefficient of DSUE is significantly positive. This indicates that investors' response to the earnings announcement may be less when market sentiment changes, supporting the investor inertia hypothesis, but the extent is not

\begin{tabular}{|c|c|c|c|c|c|c|}
\hline \multirow{3}{*}{ Variables } & \multicolumn{6}{|c|}{ Dependent Variable $=$ SAR $(-1,+1)$} \\
\hline & \multicolumn{3}{|c|}{ SENT = DSENT } & \multicolumn{3}{|c|}{ SENT $=$ CSENT } \\
\hline & Coefficient & \multicolumn{2}{|c|}{ t-Value } & \multirow{2}{*}{$\begin{array}{c}\text { Coefficient } \\
-0.0133\end{array}$} & \multicolumn{2}{|c|}{ t-Value } \\
\hline Const. & -0.0144 & -2.43 & $* *$ & & -2.27 & ** \\
\hline DSUE & 0.0159 & 7.21 & $* * *$ & 0.0147 & 9.25 & $* * *$ \\
\hline DSUE*SENT & -0.0024 & -0.82 & & -0.0003 & -0.13 & \\
\hline DSENT & 0.0024 & 0.97 & & & & \\
\hline CSENT & -0.0003 & -0.19 & & 0.0005 & 0.37 & \\
\hline PSENT $_{t}$ & -0.0007 & -0.69 & & -0.0009 & -0.97 & \\
\hline SIZE & 0.0014 & 0.53 & & 0.0014 & 0.53 & \\
\hline VOLM & 0.0015 & 0.62 & & 0.0015 & 0.61 & \\
\hline VALUE & -0.0020 & -0.73 & & -0.0020 & -0.72 & \\
\hline ROA & 0.0012 & 0.63 & & 0.0012 & 0.63 & \\
\hline МТВ & -0.0057 & -3.02 & $* * *$ & -0.0057 & -3.01 & $* * *$ \\
\hline LEVER & 0.0050 & 2.24 & $* *$ & 0.0050 & 2.23 & $* *$ \\
\hline FOLLOW & 0.0030 & 1.31 & & 0.0029 & 1.30 & \\
\hline FOR & 0.0010 & 0.47 & & 0.0010 & 0.48 & \\
\hline BETA & -0.0046 & -2.28 & $* *$ & -0.0046 & -2.28 & $* *$ \\
\hline VOLATI & 0.0002 & 0.10 & & 0.0002 & 0.10 & \\
\hline BIG4 & -0.0020 & -1.69 & $*$ & -0.0020 & -1.69 & $*$ \\
\hline$\sum \mathrm{YR}$ & & Included & & & Included & \\
\hline$\sum$ Industry & & Included & & & Included & \\
\hline ADJ. $R^{2}$ & & $1.32 \%$ & & & $1.31 \%$ & \\
\hline Obs. & & 15,315 & & & 15,315 & \\
\hline Firm Clust. SE & & Yes & & & Yes & \\
\hline
\end{tabular}
statistically significant.

Table 9. The Change in Market Sentiment and PEAD: ERC(earnings response coefficient) test.

Note: Please refer to the variable definitions in research model 1 . The notation $*, * *$ and ${ }^{* * *}$ represent significance level at the $10 \%, 5 \%$, and $1 \%$, respectively.

\section{Conclusions}

This study investigated whether the magnitude of stock price drift is systematically different by the change in market sentiment. Positing that the continuation of the directional market sentiment 
influences investors' inertial behavior, which causes an underreaction to earnings information, we then conjectured that the post-earnings-announcement drift is systematically associated with the change in market sentiment. We employed the composite index suggested by Kim and Byun [13] as a proxy for market sentiment. To test our hypothesis, we conducted a portfolio drift test and a regression analysis using financial data from 2002 Q4 to 2017 Q4 in the Korean stock market (KSE).

Our results showed that the subsequent abnormal returns following an earnings announcement incrementally increase with the change (especially upward shift) in the market sentiment. Note that this result holds even after controlling for the effect of prior- or following-sentiment on abnormal returns. Our findings suggest that the change in market sentiment is significantly related to the PEAD, which results from the market's underreaction due to investor inertia. However, this result does not subsume the effect of prior- or following-sentiment on PEAD. Further, we showed that this result is significant just for positive unexpected earnings, indicating asymmetric PEAD due to investor inertia in the direction of unexpected earnings.

Our paper is distinctive from previous research in that we documented that PEAD is affected by the change in market sentiment, just not market sentiment for a specific point in time (i.e., prior-sentiment or following-sentiment). Our findings are useful for researchers as well as professional investors interested in understanding stock price behavior from intrinsic firms' value and trying to capture abnormal returns from market mispricing. With respect to this, we emphasize on understanding of accounting earnings information which implicitly signals future earnings.

Conclusively, by linking PEAD as one market anomaly with investor inertial behavior under changing market sentiment, our findings shed light on the relation between investor's cognitive biases in a certain environment and market anomalies. In this respect, we proposed some thesis on differential inertia effect by investor sophistication in a capital market. Specifically, prior research has documented that foreign investors are relatively superior to other investors in the emerging market. Thus, we suggest that whether they play a role in mitigating indeed PEAD magnitude due to inertia behavior is feasible as future research.

To summarize, investors are biased toward the conventional belief based on market sentiment when processing earnings information. Where, to explain market inefficiency under market sentiment change, we adopted investor inertia concept. However, ultimately what we emphasize is the role of accounting information content which involves the information about future earnings to improve market efficiency. In this respect, we suggest that properly understanding the accounting information is the instrumental factor that enables the capital market to be sustainable with the stock market working efficiently.

Most of the behavioral finance-related literature tests the hypothesis by using a single factor or multi-factors model and forming portfolios based on the explanatory variable level [54,55]. However, we consider that analyzing by regression model in an attempt to test the PEAD phenomenon, even though latently caused by investor cognitive bias, makes the internal validity of our research more enhanced. Nevertheless, we acknowledge such a limitation of our paper and encourage the extended research to use a modelling framework (i.e., behavioral model) in order to intensify our thesis.

Author Contributions: Conceptualization, H.S. (Heejeong Shin); Methodology, H.S. (Heejeong Shin); Formal Analysis, S.-I.K.; Investigation, S.-I.K. and H.S. (Heejeong Shin); Writing-Original Draft Preparation, H.S. (Hyejeong Shin); Writing-Review and Editing, H.S. (Hyejeong Shin); Project Administration, S.-I.K.

Funding: This work was supported by the Hongik University new faculty research support fund.

Conflicts of Interest: The authors declare no conflict of interest.

\section{References}

1. Ball, R.; Brown, P. An Empirical Evaluation of Accounting Income Numbers. J. Account. Res. 1968, 6, 159-178. [CrossRef] 
2. Freeman, R.; Tse, S. The Multi-Period Information Content of Earnings Announcements: Rational Delayed Reactions to Earnings News. J. Account. Res. 1989, 27, 49-79. [CrossRef]

3. Baker, M.; Coval, J.; Stein, J. Corporate Financing Decisions When Investors Take the Path of Least Resistance. J. Financ. Econ. 2007, 84, 266-298. [CrossRef]

4. Puri, M.; Kothari, T. The Physics of Economics \& Investment; Working Paper. Available online: http://www. maahinpuri.com/wp-content/uploads/2016/05/The-Physics-of-Economics-and-Investment.pdf (accessed on 20 April 2016).

5. Kim, H.H.; Maurer, R.; Mitche, O.S. Time is money: Rational life cycle inertia and the delegation of investment management. J. Financ. Econ. 2016, 121, 427-447. [CrossRef] [PubMed]

6. The Korean Economic Daily. Available online: http://land.hankyung.com/board/view.php?id=land_ specialist\&no=699 (accessed on 12 November 2012).

7. Grundy, B.D.; Martin, J.S. Understanding the Nature of the Risks and the Source of the Rewards to Momentum Investing. Rev. Financ. Std. 2001, 14, 29-78. [CrossRef]

8. Jegadeesh, N.; Titman, S. Returns to Buying Winners and Selling Losers: Implications for market efficiency. J. Financ. 1993, 48, 65-91. [CrossRef]

9. Jegadeesh, N.; Titman, S. Profitability of Momentum Strategies: An Evaluation of Alternative Explanations. J. Financ. 2001, 56, 699-720. [CrossRef]

10. Bernard, V.; Thomas, J. Evidence that Stock Prices Do not Fully Reflect the Implications of Current Earnings for Future Earnings. J. Account. Econ. 1990, 13, 305-340. [CrossRef]

11. Ahn, H.J.; Kang, J.; Ryu, D. Informed Trading in the Index Option Market: The Case of KOSPI 200 Options. J. Futures Markets 2008, 28, 1118-1146. [CrossRef]

12. Sim, M.; Ryu, D.; Yang, H. Tests on the Monotonicity Properties of KOSPI 200 Options Prices. J. Futures Markets 2016, 36, 625-646. [CrossRef]

13. Kim, K.; Byun, J. Effect of Market Sentiment on Market Response to Stock Split Announcement. Asia Pac. J. Financ. Stud. 2010, 39, 687-719. [CrossRef]

14. Foster, G.; Olsen, C.; Shevlin, T. Earnings Releases, Anomalies, and the Behavior of Security Returns. Account. Rev. 1984, 59, 574-603.

15. Bhushan, R. An Informational Efficiency Perspective on the Post-Earnings Announcement Drift. J. Account. Econ. 1994, 18, 45-65. [CrossRef]

16. Ng, J.; Rusticus, T.; Verdi, R. Implications of Transaction Costs for the Post-Earnings-Announcement Drift. J. Account. Res. 2008, 46, 661-696. [CrossRef]

17. Ball, R.; Bartov, E. How Naive is the Stock Market's Use of Earnings Information? J. Account. Econ. 1996, 21, 319-337. [CrossRef]

18. Nah, C.K. Post Earnings Announcement Drift and Time-Series Properties of Quarterly Earnings. Korean Account. Rev. 2008, 33, 111-139.

19. Lee, K.T.; Lee, Y.J. A Study of Factors Affecting Post-Earnings-Announcement Drift. Korean Account. Rev. 2008, 33, 61-102.

20. Nah, C.K.; Lee, E.C. The Effects of Audit Quality Difference on the Magnitude of Post Earnings Announcement Drift. J. Financ. Account. Inf. 2009, 9, 101-127.

21. Na, C.K.; Shin, H.J. The Effects of Foreign Ownership on the Magnitude of the Post-Earnings Announcement Drift. Korean Account. Rev. 2012, 37, 203-238.

22. Bartov, E.; Radhakrishnan, S.; Krinsky, I. Investor Sophistication and Patterns in Stock Returns after Earnings Announcements. Account. Rev. 2000, 75, 43-63. [CrossRef]

23. Kimbrough, M. The Effect of Conference Calls on Analysts and Market Under-Reaction to Earnings to Earnings Announcements. Account. Rev. 2005, 80, 189-219. [CrossRef]

24. Fung, S.; Su, L. Analysts' Activities after Earnings, Announcement and Post-Earnings-Announcement Drift; Working Paper; The Hong Kong Polytechnic University: Hong Kong, China, 2006.

25. Zhang, X.F. Information Uncertainty and Stock Returns. J. Financ. 2006, 61, 105-136. [CrossRef]

26. Ferguson, A.; Matolcsy, Z. Audit Quality and Post Earnings Announcement Drift. Asia Pac. J. Account. Econ. 2004, 11, 121-137. [CrossRef]

27. Narayanamoorthy, G.S. Conservatism and Cross-Sectional Variation in the Post-Earnings Announcement Drift. J. Account. Res. 2006, 44, 763-789. [CrossRef] 
28. Cao, S.S.; Narayanamoorthy, G.S. Earnings Volatility, Post-Earnings Announcement Drift, and Trading Frictions. J. Account. Res. 2012, 50, 41-74. [CrossRef]

29. Mikhail, M.; Walther, B.; Willis, R. Security Analyst Experience and Post-Earnings-Announcement Drift. J. Account. Audit. Financ. 2003, 18, 529-550. [CrossRef]

30. Barberis, N.; Shleifer, A.; Vishny, R. A model of investor sentiment. J. Financ. Econ. 1998, 49, 307-343. [CrossRef]

31. Daniel, K.; Hirshleifer, D.; Subrahmanyam, A. Investor Psychology and Security Market Under- and Overreactions. J. Financ. 1998, 53, 1839-1885. [CrossRef]

32. Merton, R.C. An Intertemporal Capital Asset Pricing Model. Econometrica 1973, 41, 867-887. [CrossRef]

33. Hirshleifer, D.; Teoh, S. Limited Aattention, Information Disclosure, and Financial Reporting. J. Account. Econ. 2003, 35, 337-386. [CrossRef]

34. Hirshleifer, D.; Lim, S.; Teoh, S.H. Limited Investor Attention and Stock Market Misreactions to Accounting Information. Rev. Asset Pric. Stud. 2011, 1, 35-73. [CrossRef]

35. George, T.J.; Hwang, C.Y.; Li, Y. Anchoring, the 52-Week High and Post Earnings Announcement Drift; Working Paper; University of Houston: Houston, TX, USA; Nanyang Technological University: Singapore, 2015.

36. Bilias, Y.; Georgarakos, D.; Haliassos, M. Portfolio Inertia and Stock Market Fluctuations. J. Money Credit Bank. 2010, 42, 715-742. [CrossRef]

37. Hirshleifer, D.; Welch, I. An Economic Approach to the Psychology of Change: Amnesia, Inertia, and Impulsiveness. J. Econ. Manag. Strat. 2002, 11, 379-421. [CrossRef]

38. Agnew, A.; Balduzzi, P.; Sunden, A. Portfolio Choice and Trading in a Large 401(k) Plan. Am. Econ. Rev. 2003, 93, 193-215. [CrossRef]

39. Madrian, B.C.; Shea, D.F. The Power of Suggestion: Inertia In 401(k) Participation and Savings Behavior. Q. J. Econ. 2001, 116, 1149-1187. [CrossRef]

40. Brown, G.W.; Cliff, M.T. Market Sentiment and Asset Valuation. J. Bus. 2005, 78, 405-440. [CrossRef]

41. Baker, M.; Wurgler, J. Market Sentiment and the Cross-Section of Stock Returns. J. Financ. 2006, 61, 1645-1680. [CrossRef]

42. Lemmon, M.; Portniaguina, E. Consumer Confidence and Asset Prices: Some Empirical Evidence. Rev. Financ. Stud. 2006, 19, 1499-1529. [CrossRef]

43. Mian, G.M.; Sankaraguruswamy, S. Market Sentiment and Stock Market Response to Earnings News. Account. Rev. 2012, 87, 1357-1384. [CrossRef]

44. Park, S. Market sentiment and the Market Pricing of Corporate Earnings. Korean Account. J. 2016, 2, 117-149.

45. Thorp, W.A. Investor Sentiment as a Contrarian Indicator; The American Association of Individual Investors: Chicago, IL, USA, 2004.

46. Akerlof, G.A. Procrastination and Obedience. Am. Econ. Rev. 1991, 81, 1-19.

47. Baker, M.; Wurgler, J. Market Sentiment in the Stock Market. J. Econ. Perspect. 2007, 21, 129-151. [CrossRef]

48. Petersen, M.A. Estimating Standard Errors in Finance Panel Data Sets: Comparing Approaches. Rev. Financ. Stud. 2009, 22, 435-480. [CrossRef]

49. Fama, E.; French, K. The Cross-Section of Expected Stock Returns. J. Financ. 1992, 47, 427-465. [CrossRef]

50. Haugen, R.; Baker, N. Commonality in the Determinants of Expected Stock Returns. J. Financ. Econ. 1996, 41, 401-439. [CrossRef]

51. Durbin, J.; Watson, G.S. Testing for Serial Correlation in Least Squares Regression: I. Biometrika 1950, 37 , 409-428. [PubMed]

52. Wooldridge, J.M. Introductory Econometrics: A Modern Approach, 5th ed.; South-Western: Cengage Learning, NJ, USA, 2012.

53. Greene, W.H. Econometric Analysis, 5th ed.; Prentice Hall: Upper Saddle River, NJ, USA, 2003.

54. Chan, W.S.; Frankel, R.; Kothari, S.P. Testing behavioral finance theories using trends and consistency in financial performance. J. Account. Econ. 2004, 38, 3-50. [CrossRef]

55. Kariofyllas, S.; Philippas, D.; Siriopoulos, C. Cognitive biases in investors' behaviour under stress: Evidence from the London Stock Exchange. Int. Rev. Financ. Anal. 2017, 54, 54-62. [CrossRef]

(C) 2019 by the authors. Licensee MDPI, Basel, Switzerland. This article is an open access article distributed under the terms and conditions of the Creative Commons Attribution (CC BY) license (http://creativecommons.org/licenses/by/4.0/). 